\title{
Corrigendum: Insulin Action, Glucose Homeostasis and Free Fatty Acid Metabolism: Insights From a Novel Model
}

\section{OPEN ACCESS}

Edited and reviewed by: Marcus M. Seldin, University of California, Irvine, United States

*Correspondence: Darko Stefanovski sdarko@upenn.edu

${ }^{\dagger}$ These authors have contributed equally to this work

Specialty section: This article was submitted to Systems Endocrinology,

a section of the journal

Frontiers in Endocrinology

Received: 04 October 2021 Accepted: 15 October 2021 Published: 27 October 2021

Citation:

Stefanovski $D$

Punjabi NM, Boston RC and Watanabe RM (2021) Corrigendum: Insulin Action, Glucose Homeostasis and Free Fatty Acid Metabolism Insights From a Novel Model.

Front. Endocrinol. 12:789390. doi: 10.3389/fendo.2021.789390

\section{Darko Stefanovski ${ }^{1 *}$, Naresh M. Punjabi ${ }^{2}$, Raymond C. Boston ${ }^{1 \dagger}$ and Richard M. Watanabe ${ }^{3+}$}

\begin{abstract}
1 School of Veterinary Medicine, University of Pennsylvania, New Bolton Center, PA, United States, ${ }^{2}$ Division of Pulmonary and Critical Care Medicine, Johns Hopkins University School of Medicine, Baltimore, MD, United States, ${ }^{3}$ Department of Preventive Medicine, Keck School of Medicine of USC, Los Angeles, CA, United States
\end{abstract}

Keywords: free fatty acids (FFA), insulin action, FFA metabolism, glucose, lipolysis

\section{A Corrigendum on}

Insulin Action, Glucose Homeostasis and Free Fatty Acid Metabolism: Insights From a Novel Model

By Stefanovski D, Punjabi NM, Boston RC and Watanabe RM (2021). Front. Endocrinol. 12:625701. doi: 10.3389/fendo.2021.625701

In the original article, there was a mistake in Table 2 as published. The units for parameter $\alpha$ and $S I_{F F A}$. The corrected Table 2 appears below.

The authors apologize for this error and state that this does not change the scientific conclusions of the article in any way. The original article has been updated.

Publisher's Note: All claims expressed in this article are solely those of the authors and do not necessarily represent those of their affiliated organizations, or those of the publisher, the editors and the reviewers. Any product that may be evaluated in this article, or claim that may be made by its manufacturer, is not guaranteed or endorsed by the publisher.

Copyright $(2021$ Stefanovski, Punjabi, Boston and Watanabe. This is an open-access article distributed under the terms of the Creative Commons Attribution License (CC BY). The use, distribution or reproduction in other forums is permitted, provided the original author(s) and the copyright owner(s) are credited and that the original publication in this journal is cited, in accordance with accepted academic practice. No use, distribution or reproduction is permitted which does not comply with these terms. 
TABLE 2 | Mean \pm SE parameter estimates $(n=25)$.

\begin{tabular}{lc} 
Parameter & Value \pm SE \\
\hline$\alpha$ & $1.0 \mathrm{E}-01 \pm 1.0 \mathrm{E}-02$ \\
$S_{F F A}$ & $2.0 \mathrm{E}-02 \pm 2.0 \mathrm{E}-03$ \\
$p_{X F C R}$ & $6.0 \mathrm{E}-02 \pm 1.0 \mathrm{E}-02$ \\
$P_{X a}$ & $3.4 \mathrm{E}-05 \pm 1.1 \mathrm{E}-05$ \\
$S_{\text {FFA }}$ & $5.3 \mathrm{E}+00 \pm 7.8 \mathrm{E}-01$
\end{tabular}

Units

FSD \pm SE

$\mathrm{mmol} / \mathrm{I}^{-1}$

$\min ^{-1}$

$\min ^{-1}$

$\mathrm{pmol} / \mathrm{I}^{-1} \cdot \mathrm{min}^{-2}$

$10^{-4} \cdot \mathrm{pmol}^{-1} \mathrm{I}^{-1} \cdot \mathrm{min}^{-1}$
$0.09 \pm 0.02$

$0.11 \pm 0.01$

$0.17 \pm 0.02$

$0.08 \pm 0.01$

$0.11 \pm 0.02$ 